\title{
Mowat-Wilson syndrome: growth charts
}

Ivan Ivanovski ${ }^{1,2,3+}$, Olivera Djuric ${ }^{4,5+}$, Serena Broccoli ${ }^{4+}$, Stefano Giuseppe Caraffi ${ }^{1 \dagger}$, Patrizia Accorsi ${ }^{6}$, Margaret P. Adam ${ }^{7}$, Kristina Avela ${ }^{8}$, Magdalena Badura-Stronka ${ }^{9}$, Allan Bayat ${ }^{10,11}$, Jill Clayton-Smith ${ }^{12,13}$, Isabella Cocco ${ }^{6}$, Duccio Maria Cordelli ${ }^{14}$, Goran Cuturilo ${ }^{15,16}$, Veronica Di Pisa ${ }^{13}$, Juliette Dupont Garcia ${ }^{17}$, Roberto Gastaldi ${ }^{18}$, Lucio Giordano ${ }^{6}$, Andrea Guala ${ }^{19}$, Christina Hoei-Hansen ${ }^{20}$, Mie Inaba ${ }^{21}$, Alessandro lodice ${ }^{22}$, Jens Erik Klint Nielsen ${ }^{23}$, Vladimir Kuburovic ${ }^{24,25}$, Brissia Lazalde-Medina ${ }^{26}$, Baris Malbora ${ }^{27}$, Seiji Mizuno ${ }^{21}$, Oana Moldovan ${ }^{17}$, Rikke S. Møller ${ }^{28,29}$, Petra Muschke ${ }^{30}$, Valeria Otelli ${ }^{31}$, Chiara Pantaleoni ${ }^{32}$, Carmelo Piscopo ${ }^{33}$, Maria Luisa Poch-Olive ${ }^{34}$, Igor Prpic ${ }^{35}$, Purificación Marín Reina ${ }^{36}$, Federico Raviglione ${ }^{37}$, Emilia Ricci ${ }^{14}$, Emanuela Scarano ${ }^{38}$, Graziella Simonte ${ }^{1,39}$, Robert Smigiel ${ }^{40}$, George Tanteles ${ }^{41}$, Luigi Tarani ${ }^{42}$, Aurelien Trimouille $^{43,44}$, Elvis Terci Valera ${ }^{45}$, Samantha Schrier Vergano ${ }^{46,47}$, Karin Writz ${ }^{48}$, Bert Callewaert ${ }^{49,50}$, Salvatore Savasta ${ }^{51}$, Maria Elisabeth Street ${ }^{52}$, Lorenzo lughetti ${ }^{53,54}$, Sergio Bernasconi ${ }^{55}$, Paolo Giorgi Rossi ${ }^{4}$ and Livia Garavelli ${ }^{*}$

\section{Abstract}

Background: Mowat-Wilson syndrome (MWS; OMIM \#235730) is a genetic condition caused by heterozygous mutations or deletions of the ZEB2 gene. It is characterized by moderate-severe intellectual disability, epilepsy, Hirschsprung disease and multiple organ malformations of which congenital heart defects and urogenital anomalies are the most frequent ones. To date, a clear description of the physical development of MWS patients does not exist. The aim of this study is to provide up-to-date growth charts specific for infants and children with MWS. Charts for males and females aged from 0 to 16 years were generated using a total of 2865 measurements from 99 MWS patients of different ancestries. All data were collected through extensive collaborations with the Italian MWS association (AIMW) and the MWS Foundation. The GAMLSS package for the R statistical computing software was used to model the growth charts. Height, weight, body mass index (BMI) and head circumference were compared to those from standard international growth charts for healthy children.

Results: In newborns, weight and length were distributed as in the general population, while head circumference was slightly smaller, with an average below the 30th centile. Up to the age of 7 years, weight and height distribution was shifted to slightly lower values than in the general population; after that, the difference increased further, with $50 \%$ of the affected children below the 5 th centile of the general population. BMI distribution was similar to that of non-affected children until the age of 7 years, at which point values in MWS children increased with a less steep slope, particularly in males. Microcephaly was sometimes present at birth, but in most cases it (Continued on next page)

\footnotetext{
* Correspondence: livia.garavelli@ausl.re.it

${ }^{+}$Ivan Ivanovski, Olivera Djuric, Serena Broccoli and Stefano Giuseppe Caraffi contributed equally to this work.

'Medical Genetics Unit, Department of Mother and Child, Azienda Unità

Sanitaria Locale - IRCCS di Reggio Emilia, Viale Risorgimento, 8042123 Reggio Emilia, Italy

Full list of author information is available at the end of the article
}

(c) The Author(s). 2020 Open Access This article is licensed under a Creative Commons Attribution 4.0 International License, which permits use, sharing, adaptation, distribution and reproduction in any medium or format, as long as you give appropriate credit to the original author(s) and the source, provide a link to the Creative Commons licence, and indicate if changes were made. The images or other third party material in this article are included in the article's Creative Commons licence, unless indicated otherwise in a credit line to the material. If material is not included in the article's Creative Commons licence and your intended use is not permitted by statutory regulation or exceeds the permitted use, you will need to obtain permission directly from the copyright holder. To view a copy of this licence, visit http://creativecommons.org/licenses/by/4.0/ The Creative Commons Public Domain Dedication waiver (http://creativecommons.org/publicdomain/zero/1.0/) applies to the data made available in this article, unless otherwise stated in a credit line to the data. 
(Continued from previous page)

developed gradually during infancy; many children had a small head circumference, between the 3rd and the 10th centile, rather than being truly microcephalic (at least 2 SD below the mean). Most patients were of slender build.

Conclusions: These charts contribute to the understanding of the natural history of MWS and should assist pediatricians and other caregivers in providing optimal care to MWS individuals who show problems related to physical growth. This is the first study on growth in patients with MWS.

Keywords: Mowat-Wilson syndrome, ZEB2, Growth charts, Weight, Length, Height, Head circumference, Body mass index, BMI

\section{Background}

Mowat-Wilson syndrome (MWS; OMIM \#235730) is a rare autosomal dominant disorder caused by haploinsufficency in the $Z E B 2$ gene located on chromosome 2. It is characterized by distinctive facial features, moderate-tosevere intellectual disability, epilepsy, Hirschsprung disease and multiple congenital anomalies, including genital anomalies, congenital heart defects, agenesis of the corpus callosum and eye defects. Since the first report in 1998, more than 350 individuals have been described in the literature [1-8].

The incidence of MWS is estimated to be 1:50.00070.000 live births [9].
Several studies have reported the presence of short stature in MWS patients. In a recent article [7], which included the clinical data of 87 patients with MWS, we demonstrated that basic growth parameters - weight, length or height, body mass index (BMI), head circumference - are often normal at birth, but have a tendency to descend well below the normal range in childhood and later on. These results urged us to extend our study and construct growth charts specific for MWS.

Growth charts specific for a disease are fundamental instruments in order to monitor growth and observe deviations from normal patterns [10-20]. They allow clinicians to advise parents concerning growth expectations
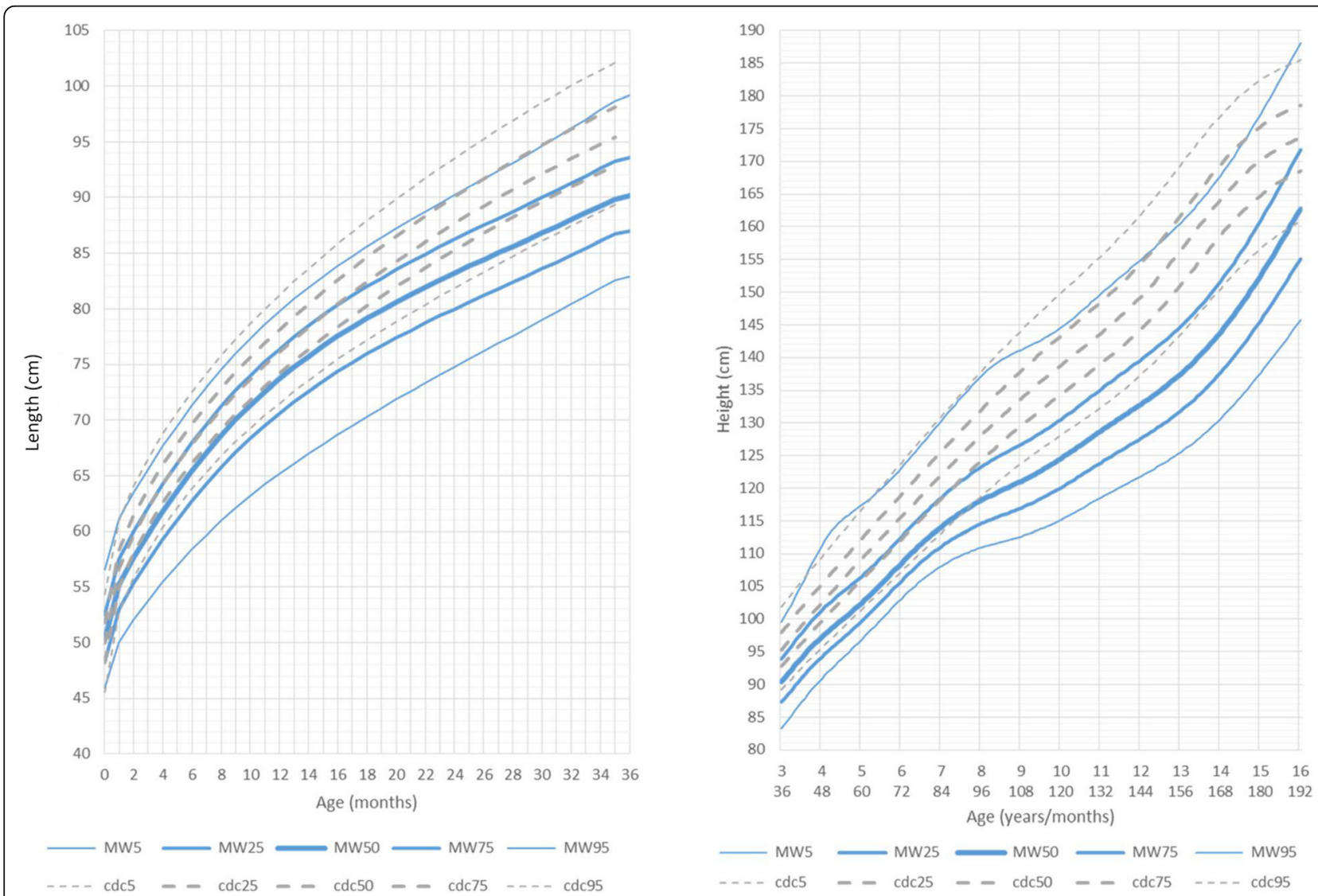

Fig. 1 Constructed length and height growth charts for MWS patients in relation to the CDC reference charts (black) for males (blue) 
for their children, and they can be very useful even in a group of patients for whom growth anomalies are not the most severe problem. Moreover, these charts describe the natural history of the disease.

The aim of this study was to provide a growth reference for MWS patients. We collected the measurements of 99 MWS patients from 20 countries and developed specific growth charts that describe the natural history of height, weight, BMI and head circumference in MWS.

\section{Methods}

\section{Study population}

Growth data of MWS patients previously published by our workgroup were incorporated into this study [7]. An invitation to participate in the study, explaining its purpose and design, was sent to all our colleagues who had a previous history of publications on MWS. Furthermore, the Italian Mowat-Wilson Association (AIMW) and the MWS Foundation forwarded the invitation to their members. To those who agreed to participate, we sent a specially designed questionnaire where they could insert the length/height, weight and head circumference measurements of patients at different ages. The collected data were reviewed and assembled in a password-protected database. Whenever we detected inconsistencies, probable errors or missing data, we contacted the family/referring doctor for corrections and further information, if needed. Only individuals with both clinical and molecular confirmation of the disease were included in the study. Two patients were excluded since the causative $Z E B 2$ variant could not be found despite molecular testing.

A total of 20 nationalities were represented in this study: 38 Italian patients, 16 from the USA, 7 from Poland, 6 from Japan, 5 from Denmark, 4 from Spain, 4 from the UK, 3 from Portugal, 3 from Finland, 2 from Croatia, 2 from Serbia, and 1 each from Albania, Brazil, Chile, Cyprus, France, Germany, Mexico, Turkey and Ukraine. None of the affected individuals originated from a consanguineous family. One Italian family comprised two affected siblings. None of the patients had ever been treated with growth hormone.

A total of 99 patients were included in the study, 53 females and 46 males, born between 1986 and 2016. A total of 2865 measurements were available: 1220 data points from 46 males and 1645 data points from $53 \mathrm{fe}$ males. These patients had a mean age of 12 years (range 4-20 years) in males and 13 years (range $3-23$ years) in females at the time of assessment.

A total of 1013 height measurements (573 for females, 440 for males), 1110 weight measurements (631 for
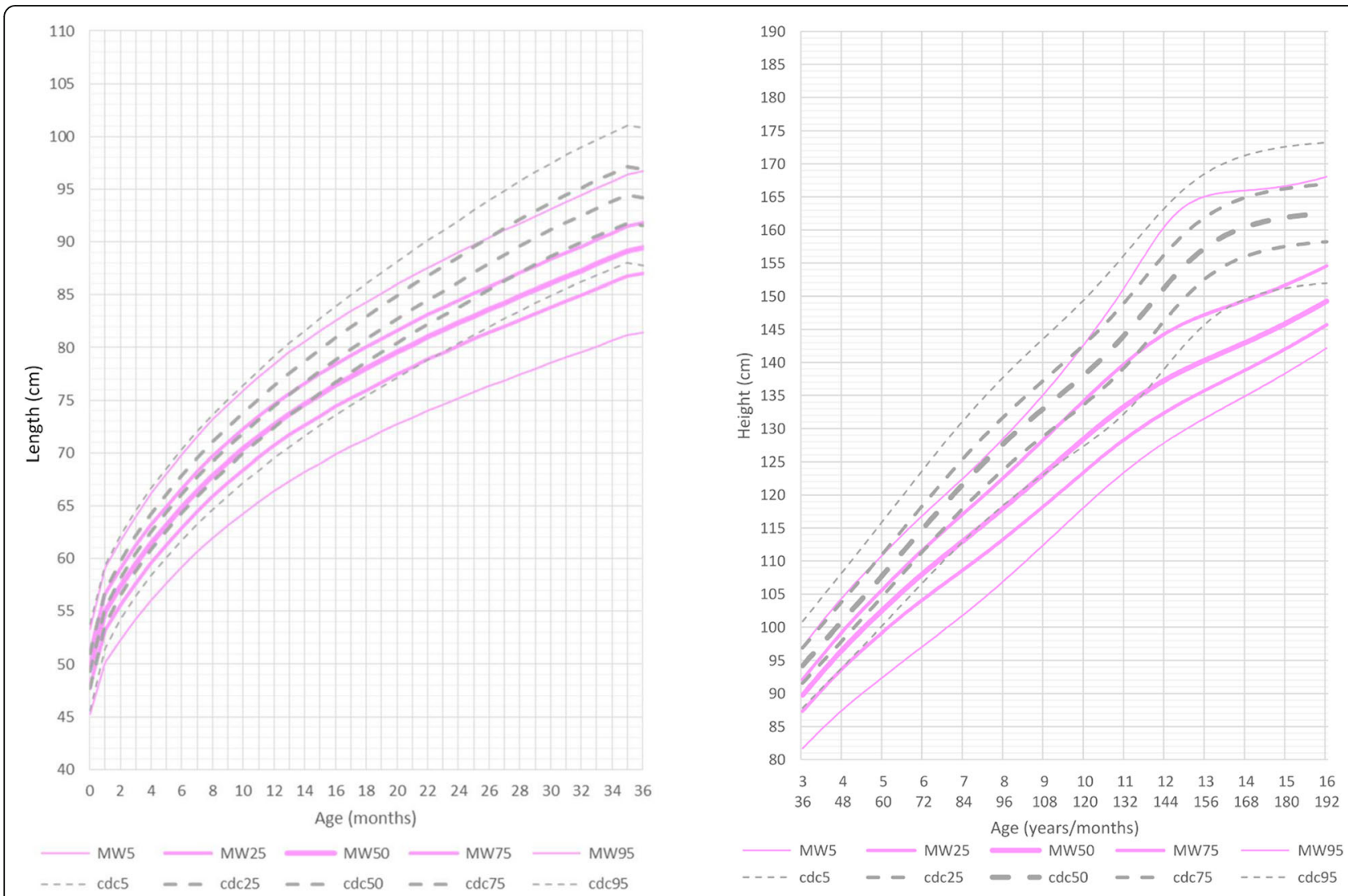

Fig. 2 Constructed length and height growth charts for MWS patients in relation to the CDC reference charts (black) for females (pink) 
females, 479 for males), and 742 head circumference measurements (441 for females, 301 for males) were available. We gathered measurements from at least 2 time points in 97 patients, and from more than 4 time points in 89 patients. For each patient we had an average of 10.39 (SD 6.52) height measurements, 11.37 (SD 6.77) weight measurements, and 7.64 (SD 5.76) head circumference measurements (Additional file 1 Table 1).

Due to limited data availability, no growth curves could be generated for individuals with MWS past the age of 16 years.

Data from 1986 to 2019 were included. Height, weight and head circumference parameters were analyzed from birth until 23 years of age, both for males and females. BMI was calculated from these data, using the formula $\mathrm{BMI}=\operatorname{mass}(\mathrm{kg}) /(\text { height }(\mathrm{m}))^{2}$.

Distribution centiles for weight, length and head circumference at birth were computed including preterm and at term newborns, i.e. from 32 to 42 gestational weeks (mean 36.5), and presented separately for males and females.

The data after birth were divided into different age and sex groups, with 1-month intervals during the first year of life, 3-month intervals during the 2nd and 3rd years of life, and 6-month intervals between the 4th and 23rd years of life.

Our growth charts were compared with the reference percentiles for anthropometric measurements in healthy children provided by the Centers for Disease Control and Prevention (CDC), with a few exceptions: for neonatal anthropometric assessment we referred to the Italian Neonatal Study (INeS) growth charts, data on head circumference in males and females aged between 3 and 16 years were compared with the Tanner reference percentiles, and standard deviations of the head circumference in males and females aged between birth and 18 years were compared with the Nellhaus reference standard deviations [21-28].

\section{Statistical analysis}

The growth charts were developed using the Generalized Additive Models for Location, Scale and Shape (GAMLSS) [29, 30] package for the R statistical computing software [31].

Centile estimation of anthropometric data $Y$ (weight, length, BMI and head circumference) for any given age was:

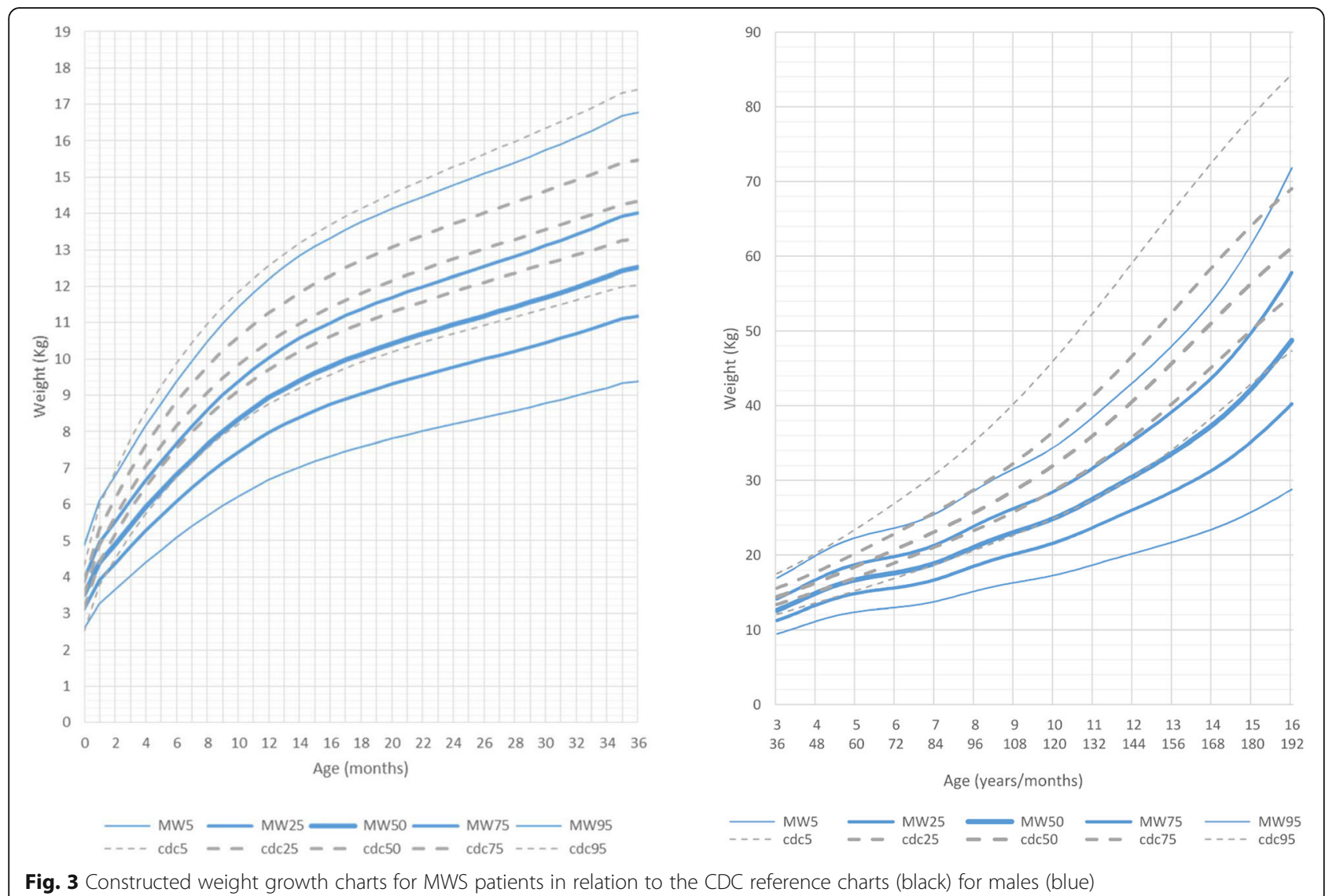




$$
\begin{aligned}
& \mathrm{Y} \sim \mathrm{D}(\mu, \delta, v, \mathrm{\tau}) \\
& \mathrm{g}_{1}(\mu)=\mathrm{h}_{1}(\mathrm{x}) \\
& \mathrm{g}_{2}(\delta)=\mathrm{h}_{2}(\mathrm{x}) \\
& \mathrm{g}_{3}(v)=\mathrm{h}_{3}(\mathrm{x}) \\
& \mathrm{g}_{4}(\mathrm{\tau})=\mathrm{h}_{4}(\mathrm{x}) \\
& \mathrm{x}=a g e^{\zeta}
\end{aligned}
$$

where the distribution $D$ represents the best general probability (density) function according to Akaike Information Criterion (AIC) and $\mu$ the first parameter of the distribution (usually location), $\delta$ the second parameter of the distribution (usually scale, coefficient of variation), $v$ the third parameter of the distribution (usually shape, e.g. skewness), $\tau$ the fourth parameter of the distribution (usually shape, e.g. kurtosis).

The $g($ ) functions represent appropriate link functions, $h()$ are non-parametric smoothing functions and $\xi$ is a power transformation of age (Additional file 2 Table 2).

The more traditional LMS method developed by Cole and Green [32] can be fitted within this framework by assuming that the response variable has a Box-Cox Cole and Green distribution [33, 34]. Additional file 2 Table 2 describes the model specifications by anthropometric measure and sex. The $\mathrm{Q}$ test was conducted to evaluate the fit of the model [35].

The estimated centiles by age and sex were converted back to Excel to create charts for each anthropometric variable, including the reference $\mathrm{CDC}$ growth charts for healthy children.

\section{Results}

\section{Length, weight and head circumference at birth}

Information on weight at birth was available for $47 \mathrm{fe}$ males and 35 males. Information on length at birth was available for 47 females and 31 males. Information on head circumference at birth was available for 40 females and 26 males.

The average gestational age was 39 weeks, with a range between 32 and 42. Gestational age in MWS was completely comparable to that of the general population.

Weights at birth were found to be within the normal range in both males and females. The average weight in males was $3288 \mathrm{~g}$, with a range between $1850 \mathrm{~g}$ and $4500 \mathrm{~g}$; the average weight in females was $3340 \mathrm{~g}$, with a range between $1620 \mathrm{~g}$ and $4060 \mathrm{~g}$. The birth weight of all males was between the 2nd and 100th centiles for gestational age (mean 51st centile); the females' birth weight
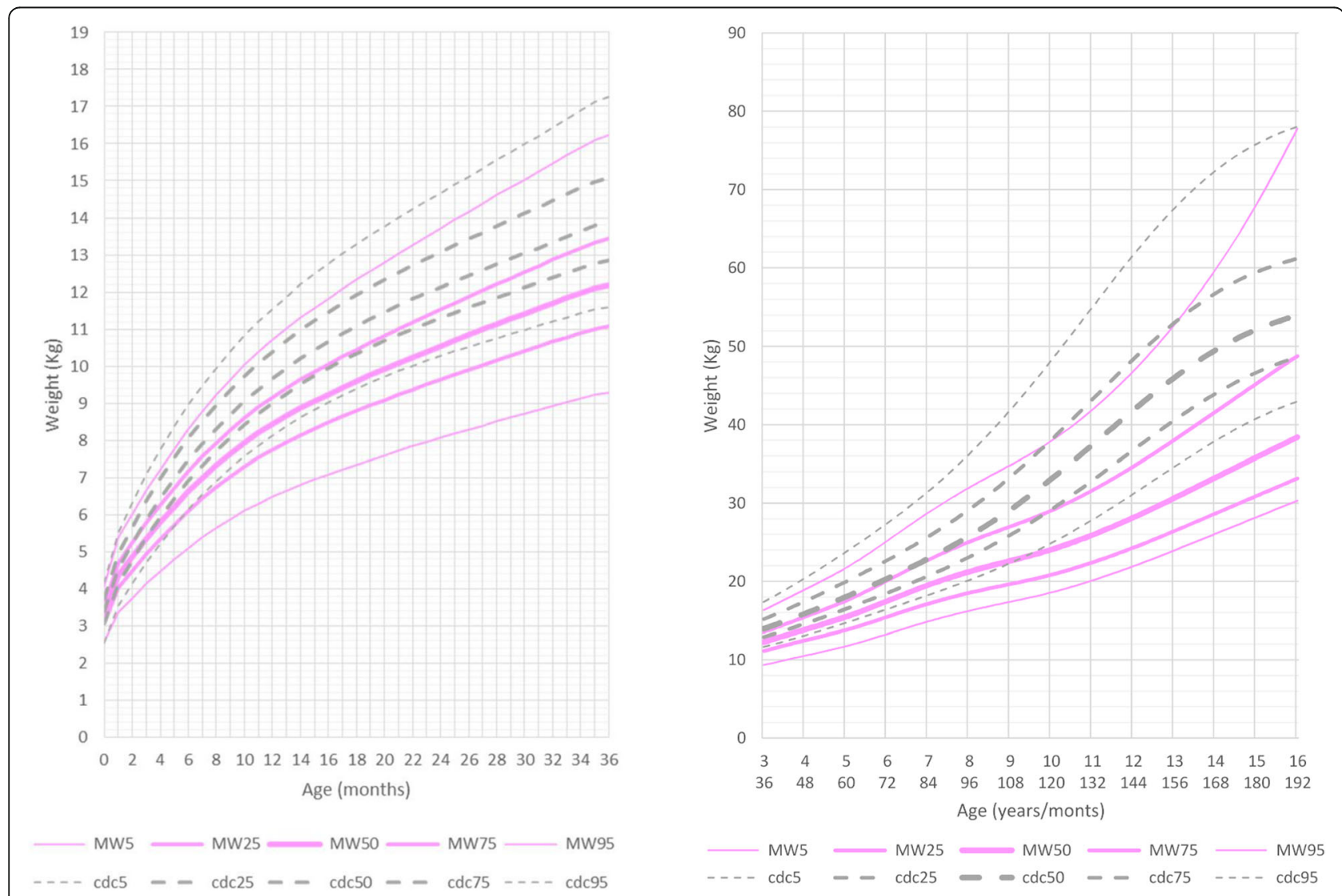

Fig. 4 Constructed weight growth charts for MWS patients in relation to the CDC reference charts (black) for females (pink) 
was between the 3rd and 100th centiles (mean 54th centile).

Length at birth was within the normal range for the vast majority of patients, both males and females. The average birth length in males measured $50 \mathrm{~cm}$, with a range between 43 and $56 \mathrm{~cm}$ (range 2nd to 99th centile, mean 44th centile). The average birth length in females was $49.1 \mathrm{~cm}$, with a range between 41 and $54 \mathrm{~cm}$ (range $<1$ st to 100th centile, mean 53rd centile).

Despite the fact that in both sexes the average head circumference at birth was within the normal range, most patients were under the 50th centile, with mean values at the 27 th centile for males and 31 st for females. In males, the mean was $33.2 \mathrm{~cm}$, with a range between 28.5 and $36 \mathrm{~cm} \quad(<1$ st to 96 th centile); in females, the mean was $33.7 \mathrm{~cm}$, with a range between 28.5 and $36 \mathrm{~cm}$ $(<1$ st to 100 th centile) .

\section{Length and height}

The mean number of longitudinal measurements per patient in males was 9.56 (SD 5.51). For 45 patients we had at least 2 measurements, and for 40 patients we gathered more than 4 measurements.
The mean number of longitudinal measurements per patient in females was 11.00 (SD 7.11). For 53 patients we had at least 2 measurements, and for 48 patients we gathered more than 4 measurements.

Up to the age of 2 months, the length of both males and females was within, or just below, the normal range. Subsequently, height in males began to increase more slowly. A significant reduction in the slope of the growth curves was noted after 7 years of age, as the height of boys affected by MWS became even more distant from the reference curves of the general population (Fig. 1 and Additional file 3 Fig. RD1).

Mean height for male patients at the age of 9 years was $121 \mathrm{~cm}(<3 \mathrm{rd}$ percentile, mean reference group at 50th percentile: $133 \mathrm{~cm}$ ) and for female patients was $123.8 \mathrm{~cm}$ (3rd-5th percentile, mean reference group at 50th percentile: $130 \mathrm{~cm}$ ).

In females, from 2 months of age, height had a slower increase as in males, and subsequently diverged even further from the reference curves of the general population. A significant reduction in the slope of the growth charts was noted after 11 years of age, much later than in males. At this age, females affected by MWS became noticeably distant from the reference curves of the
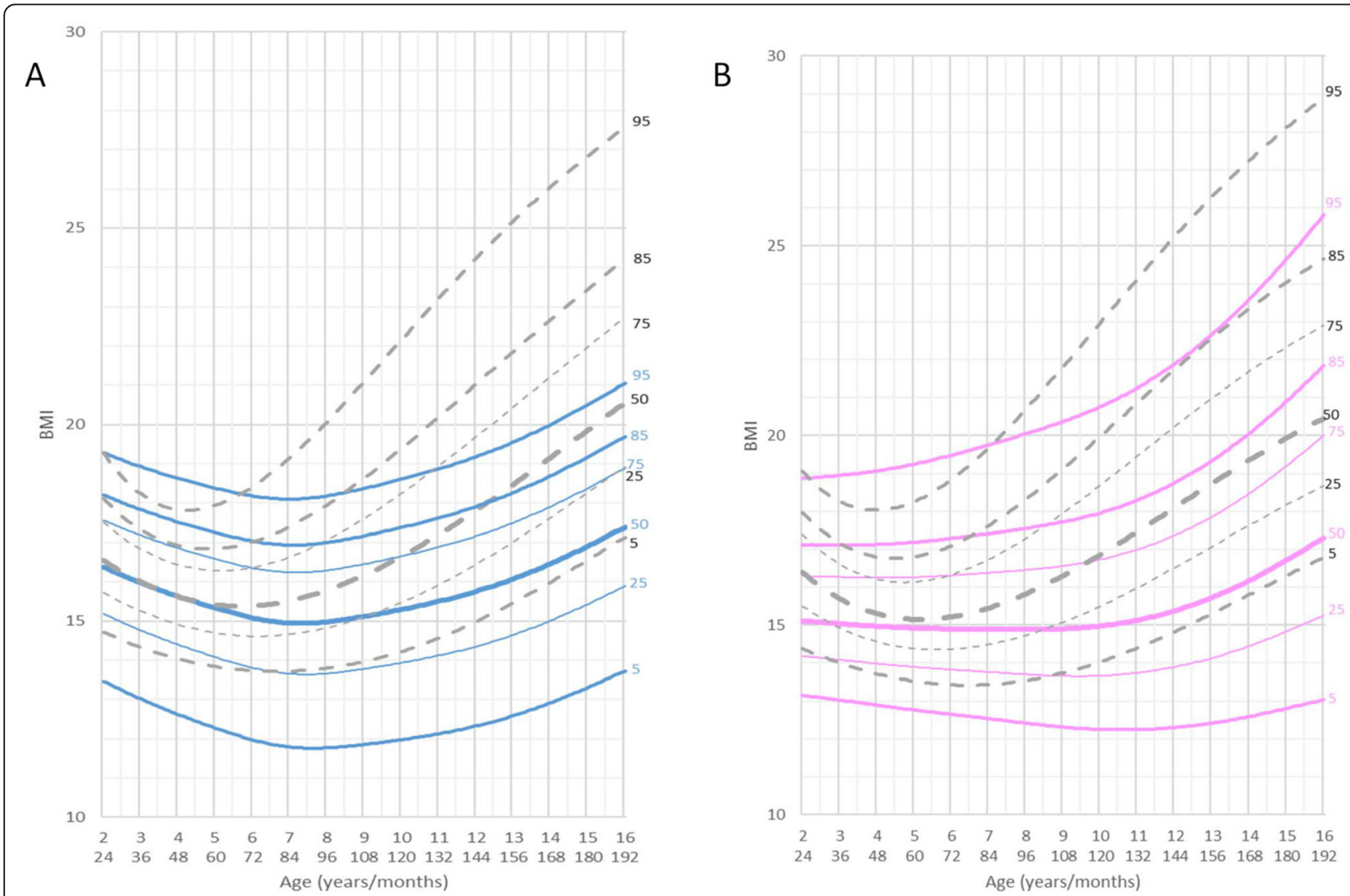

Fig. 5 Constructed charts for the BMI $\left(\mathrm{Kg} / \mathrm{m}^{2}\right)$ for MWS patients in relation to the CDC reference charts (black) a for males (blue) b for females (pink) 
general population, but were slightly less distant than males (Fig. 2 and Additional file 4 Fig. RD2).

We were not able to extend the growth charts over the age of 16 years due to the limited availability of measurements after this age. Furthermore, it is not yet possible to calculate the final height because MWS has only relatively recently been described and the data on adolescent and young adult patients is still very limited.

\section{Weight and body mass index}

The mean number of weight measurements per patient in males was 10.41 (SD 5.67). For 45 patients we had at least 2 measurements and for 41 patients we gathered more than 4 measurements.

The mean number of weight measurements per patient in females was 12.07 (SD 7.41). For 52 patients we had at least 2 measurements and for 50 patients we collected more than 4 measurements.
At age 0 to 36 months, compared to the reference group, the growth curves for weight were slightly lower than normal in both genders. Mean weight for male patients at age 5 years and 6 months was $16.800 \mathrm{~kg}$ (10th percentile, mean reference group at 50th percentile: $19.500 \mathrm{~kg}$ ) and for female patients was $15.400 \mathrm{~kg}$ (10th percentile, mean reference group at 50th percentile: $19 \mathrm{~kg})$.

After this age the growth charts flatten out considerably when compared to the normal reference group (Figs. 3 and 4, Additional file 5 Fig.RD3, Additional file 6 Fig. RD4).

At the age of 16 years both male and female patients were considerably lighter (males: mean $48 \mathrm{~kg}$ 5 th percentile, mean reference group at 50th percentile: $61 \mathrm{Kg}$; females: mean $39 \mathrm{~kg}<3 \mathrm{rd}$ percentile, mean reference group at 50th percentile: $54 \mathrm{Kg}$ ). Most patients were of slender build, with normal body proportions.

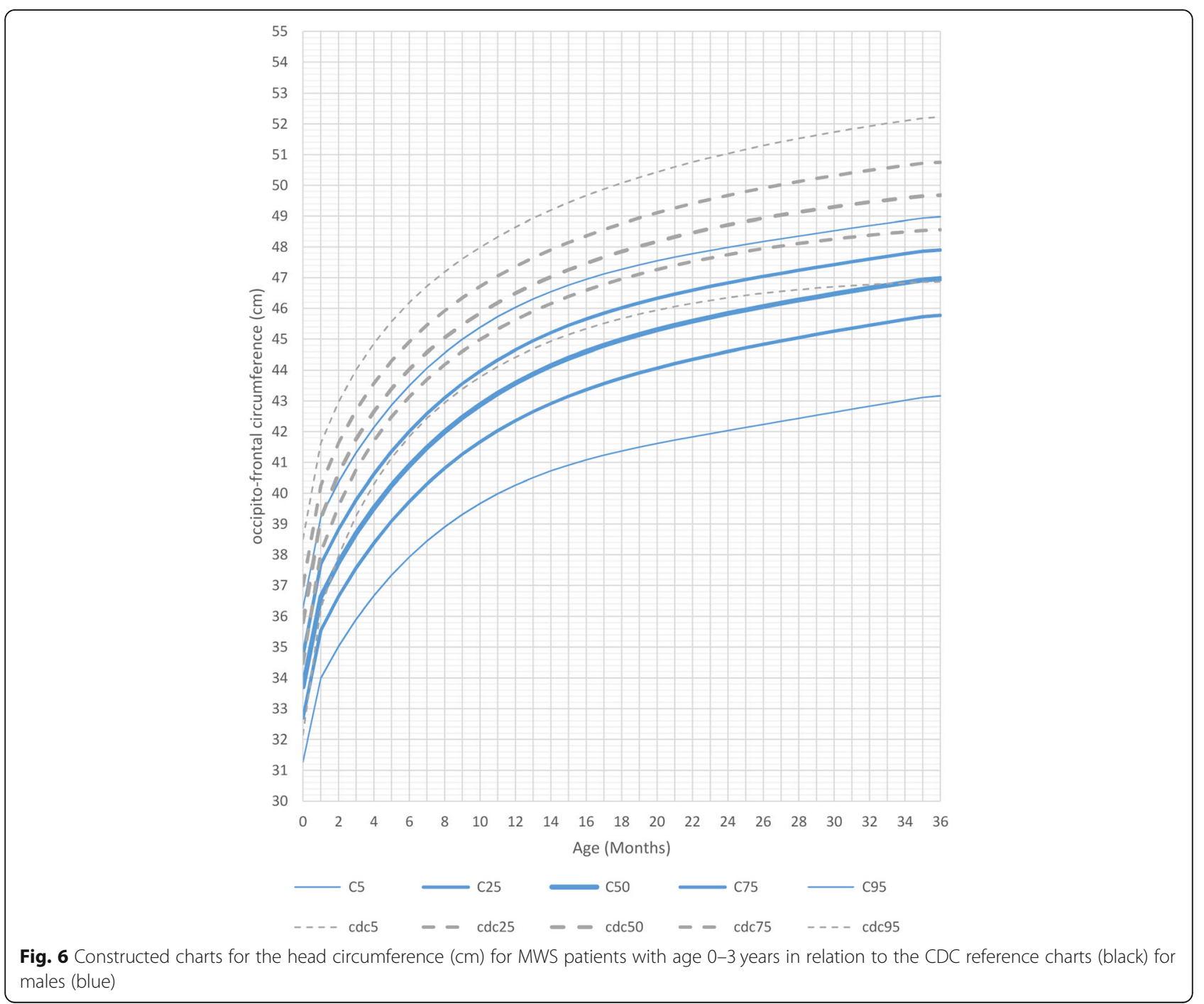


BMI in the age range 0 to 6 years was slightly lower with respect to the normal reference group. Mean BMI for male patients at 6 years of age was $15 \mathrm{~kg} / \mathrm{m}^{2}$ (mean reference group: $15.4 \mathrm{~kg} / \mathrm{m}^{2}$ ) and for female patients was $14.9 \mathrm{~kg} / \mathrm{m}^{2}$ (mean reference group: $15.3 \mathrm{~kg} / \mathrm{m}^{2}$ ). Thereafter, between the ages of 6 and 16 years, the curve for BMI flattened out significantly in both genders, but in males the shift of the curve towards lower values was more pronounced and occurred earlier, at the age of 7 years, while in females it became significant after the age of 9 years (Fig. 5).

BMI of male patients aged 16 years (mean $17.2 \mathrm{~kg} / \mathrm{m}^{2}$ ) was significantly lower compared to the reference group (mean $20.5 \mathrm{~kg} / \mathrm{m}^{2}$ ). BMI of female patients aged 16 years (mean $17.1 \mathrm{~kg} / \mathrm{m}^{2}$ ) was significantly lower compared to the reference group (mean $\left.20.5 \mathrm{~kg} / \mathrm{m}^{2}\right)$.

\section{Head circumference}

The mean number of head circumference measurements per patient in males was 6.54 (SD 4.79). For 39 patients we had at least 2 measurements, and for 31 patients we collected more than 4 measurements.

The mean number of head circumference measurements per patient in females was 8.54 (SD 6.23). For 51 patients we had at least 2 measurements, and for 41 patients we collected more than 4 measurements.

At birth, head circumference differed only slightly from the reference group in both genders. Indeed, during the first months of life, most measurements were between the 3rd and the 25th percentile of the curves for healthy controls. This changed after 1 year of age: MWS patients had a significantly smaller head circumference between the ages of 1 and 2 years. Between the ages of 2 and 3 years the curves flattened out even more and the head circumference was significantly smaller compared to healthy controls.

Mean head circumference for male patients at age 3 years was $47 \mathrm{~cm}$ (5th percentile, <-2SD, mean reference group at 50th percentile: $50 \mathrm{~cm}$ ) and for female patients was $46 \mathrm{~cm}$ (5th percentile, $-2 \mathrm{SD}$, mean reference group at 50th percentile: $49 \mathrm{~cm}$ ) (Figs. 6 and 7 and Additional file 7 Fig. RD5 Additional file 8 Fig.RD6).

It should be noted that not all children were microcephalic (at least 2 SD below the mean).

The curves for males and females continued to flatten out in the following age ranges, up to the age of 16 years. Adolescent male patients at the age of 16 years had a mean head circumference of $52 \mathrm{~cm}(<3$ rd percentile, $<-2$ $\mathrm{SD})$, the females had a mean head circumference of 49.8 $\mathrm{cm}(<3$ rd percentile, $<-2 \mathrm{SD})$ (Figs. 8 and 9).

\section{Discussion}

Various genetic disorders are characterized by growth abnormalities. Specific growth charts developed for these conditions are useful for the clinical follow-up of these patients [10-20].

In this study, charts for height, weight, BMI and head circumference were created using a sample of 99

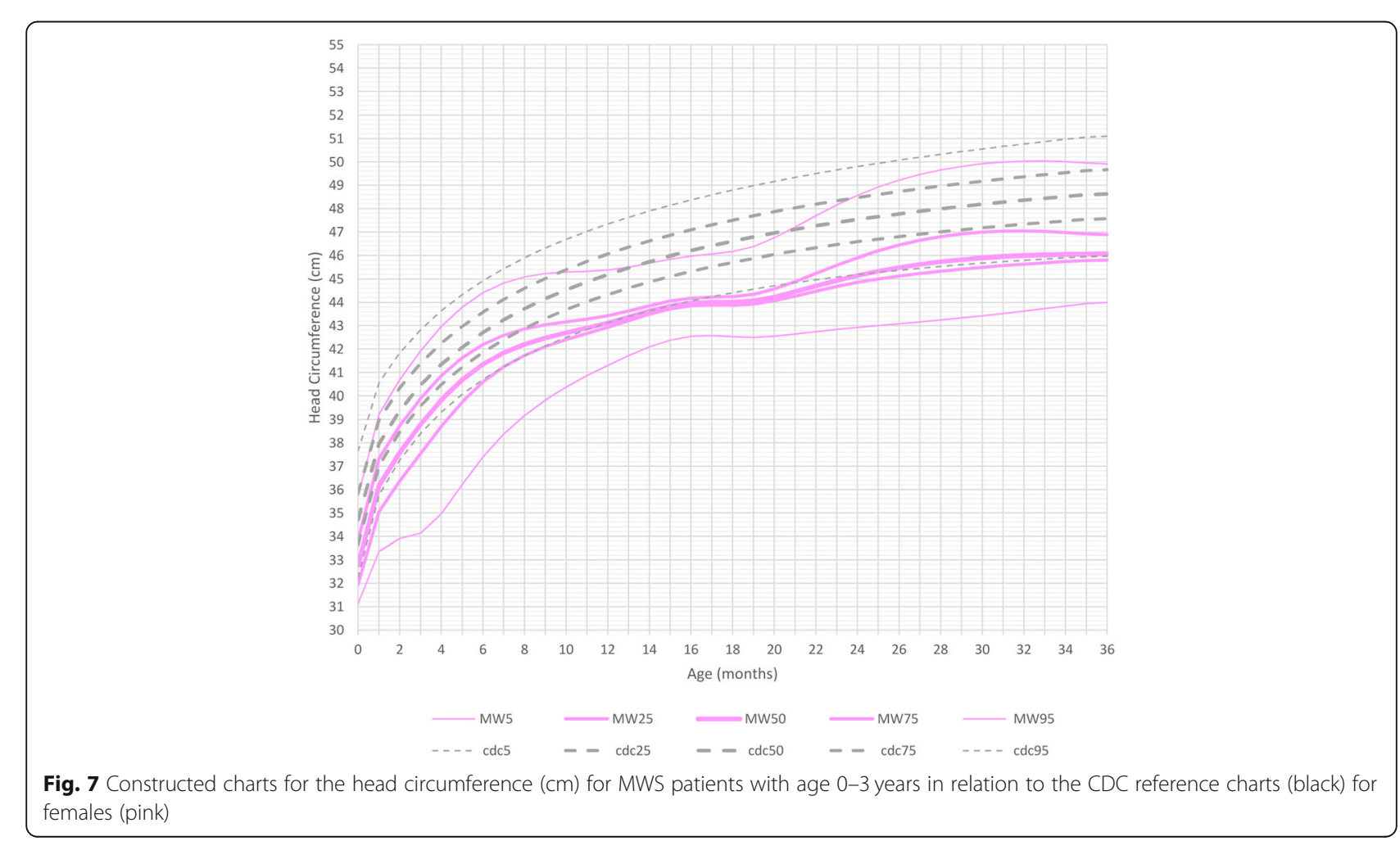




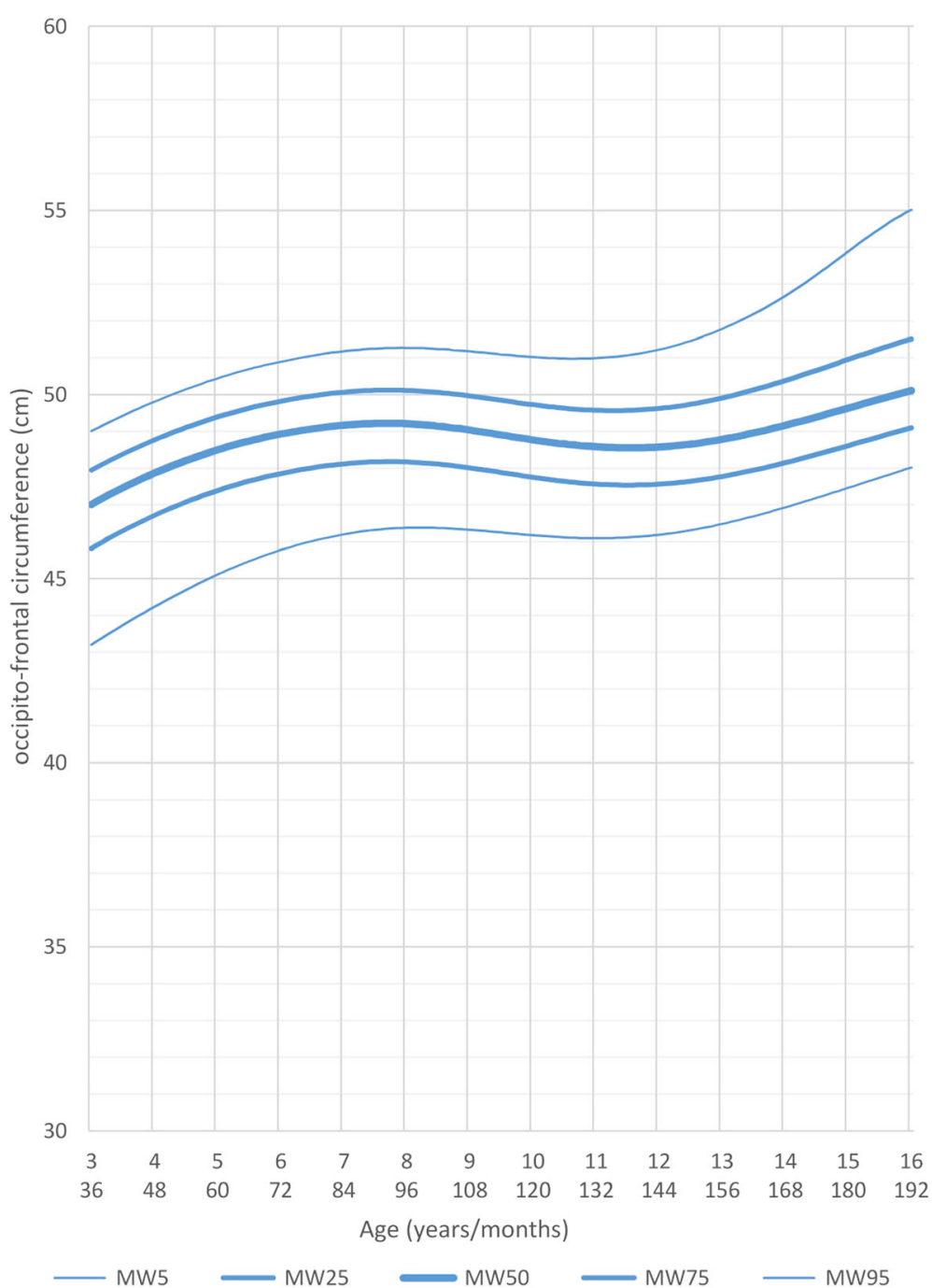

Fig. 8 Constructed charts for the head circumference (cm) for MWS patients with age 3-16 years in relation to the Tanner reference charts (black) for males (blue)

patients whose clinical diagnosis of MWS had been confirmed through genetic or cytogenetic testing.

Typically, children affected by MWS had normal length and weight at birth, and then showed a growth delay over time. The average head circumference was already slightly smaller than in the general population at birth (3rd-25th percentile) and showed a further delay during growth, leading to a mean head circumference in MWS patients below the 3rd centile of the general population. These results indicate that intrauterine growth retardation in MWS is not a consistent finding in terms of length and weight, and only plays a minor role in terms of head circumference.

In males, since the age of 2 months, the slope of the growth curves for length underwent an initial decrease. A significant further decrease was noted after 7 years of age, as the values for height became markedly distant from the reference curves of the general population. In females we observed a similar tendency, but the delay in the height growth chart took place considerably later, after 11 years of age.

Through these length, weight and head circumference growth charts we demonstrate that postnatal growth retardation in MWS becomes evident after the second month of life, is quite pronounced after 6 months and, after 1 year of age, growth flattens out even further. Males tend to be thinner than females and they also tend to have a similar head circumference when compared to females.

In addition, we observed the absence of the growth spurt during adolescence, as has already been observed in other genetic diseases, such as Turner syndrome and SHOX-related conditions [36, 37], but we do not yet have useful and sufficient data to calculate a final height, 


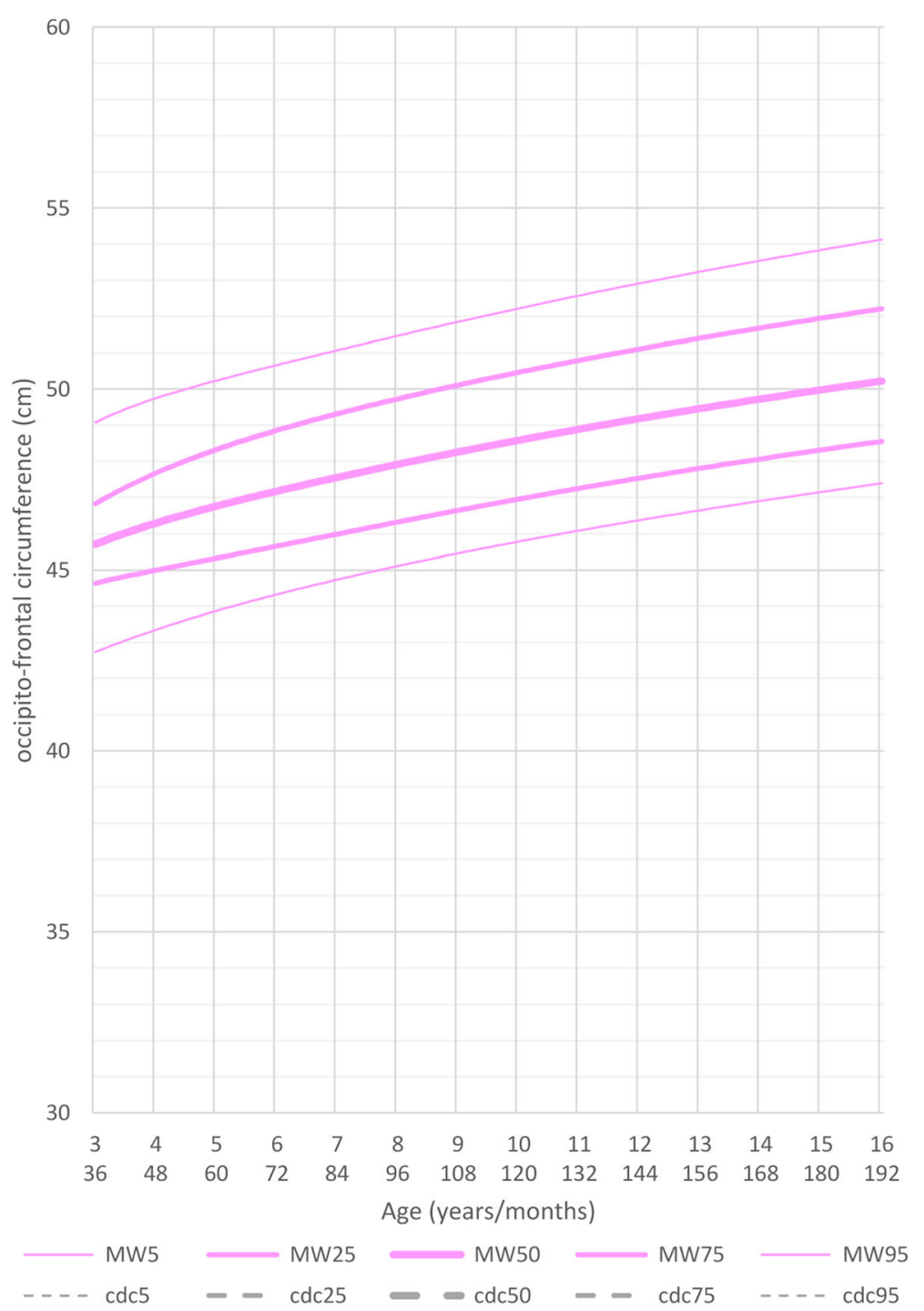

Fig. 9 Constructed charts for the head circumference $(\mathrm{cm})$ for MWS patients with age 3-16years in relation to the Tanner reference charts (black) for females (pink)

because the definition of MWS is quite recent and known adult individuals are still rare.

We also assessed BMI in MWS patients. BMI of male patients aged 16 years (mean $17.2 \mathrm{~kg} / \mathrm{m}^{2}$ ) was found to be significantly lower when compared to the reference group (mean $20.5 \mathrm{~kg} / \mathrm{m}^{2}$ ). BMI of female patients aged 16 years (mean $17.1 \mathrm{~kg} / \mathrm{m}^{2}$ ) was significantly lower compared to the reference group (mean $20.5 \mathrm{~kg} / \mathrm{m}^{2}$ ).

A limitation of the present study is the small absolute number of available subjects, which slightly reduces the precision of the growth curves, particularly in the adolescence age range. Nevertheless, this cohort includes a large portion of all well-described MWS patients in the world, and including only MWS patients with a confirmed $Z E B 2$ defect significantly increases the reliability of our results by excluding any misclassification of cases.

\section{Conclusions}

The growth charts we prepared for height, weight, BMI and head circumference may be used to assess the growth of MWS children compared to the general population.

Specific growth charts can be useful for pediatricians and clinicians in evaluating growth-related issues and in providing optimal care to MWS individuals. Furthermore, they contribute to our understanding of the natural history of MWS.

The growth charts presented here may be put to good use all over the world, however they ought to be used carefully in MWS individuals with other ethnic backgrounds. In circumstances such as these, it is essential to consider variations according to the area of origin. 


\section{Supplementary information}

Supplementary information accompanies this paper at https://doi.org/10. 1186/s13023-020-01418-4.

Additional file 1: Table S1. Number of measurements for male and female patients for height, weight and head circumference in relation to the age groups.

Additional file 2: Table S2. Model specification parameters by anthropometric measures and sex.

Additional file 3: Figure S1. RD1. Raw data of length and height (cm) for males showing the construction of the charts with individual data points.

Additional file 4: Figure S2. RD2. Raw data of length and height (cm) for females showing the construction of the charts with individual data points.

Additional file 5: Figure S3. RD3. Raw data of weight $(\mathrm{Kg})$ for males showing the construction of the charts with individual data points.

Additional file 6: Figure S4. RD4. Raw data of weight (Kg) for females showing the construction of the charts with individual data points.

Additional file 7: Figure S5. RD5. Raw data of head circumference $(\mathrm{cm})$ for males showing the construction of the charts with individual data points.

Additional file 8: Figure S6. RD6. Raw data of head circumference $(\mathrm{cm})$ for females showing the construction of the charts with individual data points.

\section{Abbreviations}

MWS: Mowat-Wilson syndrome; BMI: Body mass index; SD: Standard deviation; AIMW: Italian Mowat-Wilson syndrome association

\section{Acknowledgments}

The authors thank the Galliera Genetic Bank, member of the Telethon Genetic Biobank Network (project GTB12001), funded by Telethon Italy, and the Associazione Italiana Mowat Wilson ONLUS for assistance in managing patients' samples. We also thank all cooperating family members for contributing the medical data necessary for this study. In addition, we are grateful to Luca Valcavi for helping with the design and adaptation of the figures.

\section{Authors' contributions}

II and SGC made substantial contributions to conception, design, analysis and interpretation of data; were involved in drafting the manuscript and revising it critically for important intellectual content; OD, SB and PGR were involved in statistical drafting of the manuscript, analysis and interpretation of the data; PA, MPA, KA, MBS, AB, JCS, IC, DMC, GC, VDP, JDG, RG, LG, AG, CHH, MI Al, JEKN, VK, BLM, BM, SM, OM, RSM, PM, VO, CP, CP, MLPO, IP, MRP, $F R, E R, E S, G S, R S, G T, L T, A T, E T V, S S V, K W, B K$ and SS made substantial contributions to acquisition of data; MES, LI and SB were involved in drafting the manuscript and revising it critically for important intellectual content; LG made substantial contributions to conception and design and interpretation of data; was involved in drafting the manuscript and revising it critically for important intellectual content. The authors read and approved the final manuscript.

\section{Funding}

No funding.

\section{Availability of data and materials}

The dataset is summarized in the additional files. The raw data used during the current study are available from the corresponding author upon reasonable request.

\section{Ethics approval and consent to participate}

With resolution of the General Manager n. 0252 of 03.10 .2017 was issued the authorization to start the study, pursuant to art. 7 of the L.R. n. 9/2017. In the session of 13.09.2017, the Provincial Ethics Committee issued its favorable opinion, as per note n. 89486 of 26.09.2017.

\section{Consent for publication}

Not applicable.

\section{Competing interests}

The authors have no conflict of interest to declare.

\section{Author details}

${ }^{1}$ Medical Genetics Unit, Department of Mother and Child, Azienda Unità Sanitaria Locale - IRCCS di Reggio Emilia, Viale Risorgimento, 8042123 Reggio Emilia, Italy. ${ }^{2}$ Department of Surgical, Medical, Dental and Morphological Sciences with interest in Transplant, Oncology and Regenerative Medicine, University of Modena and Reggio Emilia, Modena, Italy. ${ }^{3}$ Institut für Medizinische Genetik, Universität Zürich, Zürich, Switzerland. ${ }^{4}$ Epidemiology Unit, Azienda Unità Sanitaria Locale - IRCCS di Reggio Emilia, Reggio Emilia, Italy. ${ }^{5}$ Center for Environmental, Nutritional and Genetic Epidemiology (CREAGEN), Section of Public Health, Department of Biomedical, Metabolic and Neural Sciences, University of Modena and Reggio Emilia, Modena, Italy. ${ }^{6}$ Neuropsychiatric Department, Spedali Civili Brescia, Brescia, Italy. ${ }^{7}$ Division of Genetic Medicine, University of Washington School of Medicine, Seattle, Washington, USA. ${ }^{8}$ Department of Clinical Genetics, Helsinki University Hospital, Helsinki, Finland. ${ }^{9}$ Chair and Department of Medical Genetics, Poznan University of Medical Sciences, Poznań, Poland. ${ }^{10}$ Institute for Regional Health Service, University of Southern Denmark, Odense, Denmark. ${ }^{11}$ Department of Epilepsy Genetics and Personalized Medicine, Danish Epilepsy Centre Dianalund, Dianalund, Denmark. ${ }^{12}$ Division of Evolution and Genomic Sciences, School of Biological Sciences, Faculty of Biology, Medicine and Health, University of Manchester, Manchester, UK. ${ }^{13}$ Manchester Centre for Genomic Medicine, St Mary's Hospital, Manchester University NHS Foundation Trust, Health Innovation Manchester, Manchester, UK. ${ }^{14}$ Child Neurology and Psychiatry Unit, Pediatric Department, St. Orsola-Malpighi Hospital, University of Bologna, Bologna, Italy. ${ }^{15}$ Faculty of Medicine, University of Belgrade, Belgrade, Serbia. ${ }^{16}$ Department of Medical Genetics, University Children's Hospital, Belgrade, Serbia. ${ }^{17}$ Serviço de Genética Médica, Departamento de Pediatria, Hospital de Santa Maria, Centro Hospitalar Lisboa Norte, Centro Académico de Medicina de Lisboa, Lisbon, Portugal. ${ }^{18}$ UOC Clinica Pediatrica, Istituto Giannina Gaslini, Genoa, Italy. ${ }^{19}$ SOC Pediatria, Ospedale Castelli, Verbania, Italy. ${ }^{20}$ Department of Paediatrics, Copenhagen University Hospital, Rigshospitalet, Denmark. ${ }^{21}$ Department of Pediatrics, Central Hospital, Aichi Human Service Center, Kasugai, Japan. ${ }^{22}$ Child Neurology and Psychiatry Unit, Azienda Unità Sanitaria Locale - IRCCS di Reggio Emilia, Reggio Emilia, Italy. ${ }^{23}$ Department of Pediatrics, Zealand University Hospital Roskilde, Roskilde, Denmark. ${ }^{24}$ Department of Cardiology, Mother and Child Health Care Institute, Belgrade, Serbia. ${ }^{25}$ Skånes universitet sjukhus, Barnkliniken, Lund, Sweden. ${ }^{26}$ Biomedical Research Unit, Mexican Institute of Social Security, Durango, Mexico. ${ }^{27}$ Department of Pediatric Hematology \& Oncology, Tepecik Training and Research Hospital, Izmir, Turkey. ${ }^{28}$ Danish Epilepsy Centre, Dianalund, Denmark. ${ }^{29}$ Institute for Regional Health Services, University of Southern Denmark, Odense, Denmark. ${ }^{30}$ Institute for Human Genetics, University Hospital Magdeburg, Magdeburg, Germany. ${ }^{31}$ ATS Bergamo, Brembana Valley district, Bergamo, Italy. ${ }^{32}$ Developmental Neurology Unit, Fondazione IRCCS Istituto Neurologico Carlo Besta, Milan, Italy. ${ }^{33}$ U.O.S.C. Medical Genetics, A.O.R.N. "A. Cardarelli", Naples, Italy. ${ }^{34}$ Department of Pediatrics, H. San Pedro, La Rioja, Logrono, Spain. ${ }^{35}$ Department of Pediatrics-Child Neurology Service, University Hospital Rijeka, Medical Faculty, University of Rijeka, Rijeka, Croatia. ${ }^{36}$ Dismorphology and Reproductive Genetics, Neonatal Research Group, Health Research Institute Hospital La Fe, University \& Polytechnic Hospital La $\mathrm{Fe}$, Valencia, Spain. ${ }^{37} \mathrm{Child}$ Neuropsychiatry Unit, U.O.N.P.I.A ASST-Rhodense, Rho, Milan, Italy. ${ }^{38}$ Unit of Pediatrics, Department of Medical and Surgical Sciences, St. Orsola-Malpighi Hospital, University of Bologna, Bologna, Italy. ${ }^{39}$ Department of Pediatrics and Medical Sciences, "Vittorio Emanuele" Hospital, University of Catania, Catania, Italy. ${ }^{40}$ Department of Pediatrics, Division Pediatric Propedeutics and Rare Disorders, Wroclaw Medical University, Wroclaw, Poland. ${ }^{41}$ Clinical Genetics Clinic, Cyprus Institute of Neurology and Genetics, Nicosia, Cyprus. ${ }^{42}$ Department of Pediatrics, University "La Sapienza,", Rome, Italy. ${ }^{43} \mathrm{CHU}$ de Bordeaux, Service de Génétique Médicale, Bordeaux, France. ${ }^{44}$ INSERM U1211, Univ. Bordeaux, Bordeaux, France. ${ }^{45}$ Department of Pediatrics, Ribeirão Preto Medical School, University of São Paulo, São Paulo, Brazil. ${ }^{46}$ Department of Pediatrics, Eastern Virginia Medical School, Norfolk, Virginia, USA. ${ }^{47}$ Division of Medical Genetics and Metabolism, Children's Hospital of The King's Daughters, Norfolk, 
Virginia, USA. ${ }^{48}$ Clinical Institute of Medical Genetics, University Medical Centre Ljubljana, Ljubljana, Slovenia. ${ }^{49}$ Center for Medical Genetics, Ghent University Hospital, Ghent, Belgium. ${ }^{50}$ Department of Biomolecular Medicine, Ghent University, Ghent, Belgium. ${ }^{51}$ Pediatric Clinic, IRCCS Policlinico "S. Matteo" Foundation, University of Pavia, Pavia, Italy. ${ }^{52}$ Division of Pediatric Endocrinology and Diabetology, Department of Mother and Child, Azienda Unità Sanitaria Locale - IRCCS di Reggio Emilia, Reggio Emilia, Italy. ${ }^{53}$ Post-graduate School of Pediatrics, University of Modena and Reggio Emilia, Modena, Italy. ${ }^{54}$ Department of Medical and Surgical Sciences of Mother, Children and Adults, Pediatric Unit, University of Modena and Reggio Emilia, Modena, Italy. ${ }^{55}$ Microbiome Research Hub, University of Parma, Parma, Italy.

Received: 12 March 2020 Accepted: 25 May 2020

Published online: 15 June 2020

\section{References}

1. Mowat DR, Croaker GD, Cass DT, Kerr BA, Chaitow J, Adès LC, et al. Hirschsprung disease, microcephaly, mental retardation, and characteristic facial features: delineation of a new syndrome and identification of a locus at chromosome 2q22-q23. J Med Genet. 1998;35:617-23.

2. Wilson M, Mowat D, Dastot-Le Moal F, Cacheux V, Kääriäinen H, Cass D, et al. Further delineation of the phenotype associated with heterozygous mutations in ZFHX1B. Am J Med Genet A. 2003;119A:257-65.

3. Zweier C, Thiel CT, Dufke A, Crow YJ, Meinecke P, Suri M, et al. Clinical and mutational spectrum of Mowat-Wilson syndrome. Eur J Med Genet. 2005;48: 97-111

4. Adam MP, Schelley S, Gallagher R, Brady AN, Barr K, Blumberg B, et al. Clinical features and management issues in Mowat-Wilson syndrome. Am J Med Genet A. 2006;140:2730-41.

5. Garavelli L, Mainardi PC. Mowat-Wilson syndrome. Orphanet J Rare Dis. 2007;2:42.

6. Garavelli L, Zollino M, Mainardi PC, Gurrieri F, Rivieri F, Soli F, et al. MowatWilson syndrome: facial phenotype changing with age: study of 19 Italian patients and review of the literature. Am J Med Genet A. 2009;149A:417-26.

7. Ivanovski I, Djuric O, Caraffi SG, Santodirocco D, Pollazzon M, Rosato S, et al. Phenotype and genotype of 87 patients with Mowat-Wilson syndrome and recommendations for care. Genet Med. 2018;20:965-75.

8. Adam MP, Conta J, Bean LJH. Mowat-Wilson syndrome. 2007 march 28, 2007 [updated 2019 July 25]. In: Pagon RA, Bird TD, Dolan CR, Stephens K, editors. GeneReviews. Seattle: University of Washington, Seattle; 2007. p. 1993.

9. Ghoumid J, Drevillon L, Alavi-Naini SM, Bondurand N, Rio M, Briand-Suleau A, et al. ZEB2 zinc-finger missense mutations lead to hypomorphic alleles and a mild Mowat-Wilson syndrome. Hum Mol Genet. 2013;22:2652-61.

10. Rongen-Westerlaken C, Corel L, van den Broeck J, Massa G, Karlberg J, Albertsson-Wihland $\mathrm{K}$, et al. Reference values for height, height velocity and weight in Turner's syndrome. Acta Paediatr. 1997;86(9):937-42.

11. Clementi M, Milani S, Mammi I, Boni S, Monciotti C, Tenconi R. Neurofibromatosis type 1 growth charts. Am J Med Genet. 1999;87(4):317-23.

12. Martin NDT, Smith WR, Cole TJ, Preece MA. New height, weight and head circumference charts for British children with Williams syndrome. Arch Dis Child. 2007;92:598-601.

13. Montano AM, Tomatsu S, Brusius A, Smith M, Orii T. Growth charts for patients affected with Morquio a disease. Am J Med Genet A. 2008; 146A(10):1286-95.

14. Verbeek S, Eilers PHC, Lawrence K, Hennekam RCM, Versteegh FGA. Growth charts for children with Ellis-van Creveld syndrome. Eur J Pediatr. 2011;170: 207-11.

15. Tarquinio D, Jones MC, Lyons Jones K, Bird LM. Growth charts for 22q11 deletion syndrome. Am J Med Genet A. 2012;158A(11):2672-81.

16. Beets $L$, Rodriguez-Fonseca $C$, Hennekam R. Growth charts for individuals with Rubinstein-Taybi syndrome. Am J Med Genet A. 2014;164A(9):2300-9.

17. Butler MG, Lee J, Manzardo AM, Gold JA, Miller JL, Kimonis V, et al. Growth charts for non-growth hormone treated Prader-Willi syndrome. Pediatrics. 2015;135(1):e126-35.

18. Quartel A, Hendriksz CJ, Parini R, Graham S, Lin P, Harmatz P. Growth charts for individuals with Mucopolysaccharidosis VI (Maroteaux-Lamy syndrome). JIMD Rep. 2015;18:1-11.
19. Zemel BS, Pipan M, Stallings VA, Hall W, Schadt K, Freedman DS, et al. Growth charts for children with Down syndrome in the United States. Pediatrics. 2015;136(5):e1204-11.

20. Muschol NM, Pape D, Kossow K, Ullrich K, Arash-Kaps L, Hennermann JB, et al. Growth charts for patients with Sanfilippo syndrome (Mucopolysaccharidosis type III). Orphanet J Rare Dis. 2019;14(1):93. https:// doi.org/10.1186/s13023-019-1065-x.

21. Nellhaus G. Head circumference from birth to 18 years. Practical composite international and interracial graphs. Pediatrics. 1968;41:106-14.

22. Tanner JM. Normal growth and techniques of growth assessment. Clin Endocrinol Metab. 1986;15(3):411-51.

23. Hauspie RC, Vercauteren M, Susanne C. Secular changes in growth. Horm Res. 1996:45(Suppl 2):8-17.

24. Kuczmarski RJ, Ogden CL, Guo SS, Grummer-Strawn LM, Flegal KM, Mei Z, et al. 2000 CDC growth charts for the United States: methods and development. National Center for Health Statistics. Vital Health Stat. 2002; 11(246):1-190.

25. Ogden CL, Kuczmarski RJ, Flegal KM, Mei Z, Grummer-Strawn LM, Curtin LR, et al. Centers for Disease Control and Prevention 2000 growth charts for the United States: improvements to the 1977 National Center for Health Statistics version. Pediatrics. 2002;109:45-60.

26. Bertino E, Spada E, Occhi L, Coscia A, Giuliani F, Gagliardi L, et al. Neonatal anthropometric charts: the Italian neonatal study compared with other European studies. J Pediatr Gastroenterol Nutr. 2010;51(3):353-61.

27. Schaffrath Rosario A, Schienkiewitz A, Neuhauser H. German height references for children aged 0 to under 18 years compared to $\mathrm{WHO}$ and CDC growth charts. Ann Hum Biol. 2011;38(2):121-30.

28. Flegal KM, Cole TJ. Construction of LMS parameters for the Centers for Disease Control and Prevention 2000 growth charts. Natl Health Stat Rep. 2013;63:1-3.

29. Rigby RA, Stasinopoulos DM. Generalized additive models for location, scale and shape (with discussion). Appl Stat. 2005;54:507-54.

30. Rigby RA, Stasinopoulos DM. Automatic smoothing parameter selection in GAMLSS with an application to centile estimation. Stat Methods Med Res. 2014:23(4):318-32

31. R Development Core Team R. A language and environment for statistical computing. Vienna: R Foundation for Statistical Computing; 2008. Available at: https://www.R-project.org.

32. Cole TJ, Green PJ. Smoothing reference centile curves: the LMS method and penalized likelihood. Stat Med. 1992;11(10):1305-19.

33. Stasinopoulos MD, Rigby B, Voudouris V, Heller G, De Bastiani F. Flexible regression and smoothing: the GAMLSS packages in R; 2015. GAMLSS for Statistical Modelling. GAMLSS for Statistical Modeling.

34. Stasinopoulos MD, Rigby RA, Heller GZ, Voudouris V, De Bastiani F. Flexible regression and smoothing: using GAMLSS in R. J Stat Softw. 2018;85:2. https://www.crcpress.com/978113819790. https://doi.org/10.18637/jss.v085. b02.

35. Royston P, Wright EM. Goodness-of-fit statistics for age-specific reference intervals. Stat Med. 2000;19:2943-62.

36. Haeusler G, Frisch H. Methods for evaluation of growth in Turner's syndrome: critical approach and review of the literature. Acta Paediatr. 1994, 83(3):309-14.

37. Kosho T, Muroya K, Nagai T, Fujimoto M, Yokoya S, Sakamoto H, et al. Skeletal features and growth patterns in 14 patients with Haploinsufficiency of SHOX: implications for the development of turner syndrome. J Clin Endocrinol Metab. 1999;84(12):4613-21.

\section{Publisher's Note}

Springer Nature remains neutral with regard to jurisdictional claims in published maps and institutional affiliations. 